\title{
CAPÍTULO 11: DIAGNÓSTICO SOBRE PERDAS PÓS-COLHEITA DE FRUTAS E HORTALIÇAS NO CEASA DE JUAZEIRO-BA
}

\section{CHAPTER 11: DIAGNOSIS OF POST-HARVEST LOSSES OF FRUITS AND VEGETABLES IN CEASA DE JUAZEIRO-BA}

\author{
Iasmim Pereira Oliveira ${ }^{1}$; Kathianny Neris de Castro $^{2}$; Julianna Cantalino dos Santos ${ }^{3}$; \\ Silvana Bélem de Oliveira Villar ${ }^{4}$
}

\begin{abstract}
Resumo
O Brasil possui uma grande extensão territorial, com solos férteis que favorecem a alta produção de alimentos, porém vem enfrentando muitas dificuldades em relação ao grande desperdício desses produtos, desde a lavoura até o consumidor. Com isso, as empresas utilizam hortifrutigranjeiros denominados Sistemas Nacionais de Centrais de Abastecimento (CEASA) para realizar a distribuição. É no Vale do São Francisco, na cidade de Juazeiro-BA que está localizada uma das maiores CEASAS do país, responsável por receber muitos alimentos de diversas regiões e distribuir ao consumidor. Assim, o presente projeto teve como objetivo, analisar e identificar as causas dos desperdícios, como também informar aos comerciantes práticas pós-colheita e os possíveis impactos relacionados ao grande amontoado de resíduos gerados. Para a concretização da pesquisa, baseou-se no método hipotético-dedutivo, promovendo uma busca de dados, formulando questionários e panfletos para ação. Como resultado, observou-se a falta de discernimento técnico e consciência pessoal, dos comerciantes e das pessoas no geral, pois a não obrigatoriedade, ocasionava o desinteresse sobre o tema. A vista disso, conclui-se que a realização de projetos como este, geram um despertar e fazem com que a comunidade possa enxergar alguns problemas e atitudes, que de certa forma já se tornaram comuns e involuntários.
\end{abstract}

Palavras-Chaves: Desperdício, Mercado do produtor, Resíduos.

\begin{abstract}
Brazil has a large territorial extension, with fertile soils that favor high food production, but it has been facing many difficulties in relation to the great waste of these products, from the farming to the consumer. As a result, companies use horticultural products called National Supply Center Systems (CEASA) to carry out distribution. One of the largest CEASAS in the country is located in the São Francisco Valley, in the city of Juazeiro-BA, which is responsible for receiving many foods from various regions and distributing them to consumers. Thus, this project aimed to analyze and identify the causes of waste, as well as to inform traders about post-harvest practices and the possible impacts related to the large pile of waste generated. The research was based on the hypothetical-deductive method, promoting a search for data, formulating questionnaires and pamphlets for action. As a result, it was observed the lack of technical discernment and personal conscience, of the merchants and people in general, since the non-binding, caused the disinterest on the subject. In view of this, it was concluded that the realization of projects such as this one generates an awakening and makes the community see some problems and attitudes, which in a certain way have already become common and involuntary.
\end{abstract}

\footnotetext{
${ }^{1}$ Tecnologia em alimentos, IF sertão-PE, mimuefs@gmail.com

2 Tecnologia em alimentos, IF sertão-PE, kathiannyneres@gmail.com

${ }^{3}$ Mestre, Professora do IF Sertão Pernambucano, juliana.cantalino@ifsertao-pe.edu.br

${ }^{4}$ Doutora, Professora do IF Sertão Pernambucano, silvana.belem@ifsertao-pe.edu.br
} 
Keywords: Waste, Producer market, Residue.

\section{Introdução}

O Vale do São Francisco possui uma alta capacidade produtiva de frutas se destacando em campo nacional, principalmente nas cidades de Juazeiro-BA e Petrolina-PE. Isto só se torna possível devido a utilização do mecanismo de irrigação e ao clima diferenciado. Com o apoio de órgãos públicos como a Companhia de Desenvolvimento dos Vales do São Francisco e do Parnaíba (Codevasf), Universidade Federal do Vale do São Francisco (Univasf) e da Empresa Brasileira de Pesquisa e Agropecuária (Embrapa-Semiárido) acabou se tornando um polo de desenvolvimento tecnológico da fruticultura irrigada (RICARDO et al. 2016).

O município de Juazeiro possui um PIB per capta de R $\$ 16.687,70$ (IBGE/2017) mas, por outro lado o município tem um IDH-M: 0,677 médio (PNUD/2010). A cidade ocupa o quarto lugar no ranking de comercialização de hortigranjeiros, se tornando essencial para o fortalecimento do mercado interno e externo (CONAB, 2019).

De acordo com o Decreto Federal $n^{\circ} 70.502 / 1972$ que regulamenta a lei $n^{\circ} 5727$ de 04.11.1971 a respeito do Sistema Nacional de Centrais de Abastecimento (CEASA). As CEASAS são empresas estatais ou de capital misto (público, privado), destinadas a aprimorar a comercialização e distribuição de produtos hortifrutigranjeiros.

Em Juazeiro se encontra um dos maiores CEASAS do Brasil - o Mercado do Produtor -, esse centro de abastecimento foi inaugurado em julho de 1984, mas só apenas em fevereiro de 1986 que foi iniciado o funcionamento administrativo. É o quarto maior do Norte/Nordeste em volume e comercialização do país. O mercado possui 1.300 comerciantes, 1.350 boxes e 250 ambulantes, em média 10 mil pessoas frequentam o local e por dia circula 200 a 250 caminhões (PREFEITURA DE JUAZEIRO, 2020).

Neste local o lixo produzido chega a aproximadamente 19 toneladas $\backslash$ dia onde $65 \%$ dele é composto por alimentos (Autarquia Municipal de Abastecimento), o que pode ser considerada uma quantia muito elevada para um país como o Brasil onde o índice de fome chega a 54\% (Instituto Brasileiro de Geografia e Estatística - IBGE 2015), e no município de juazeiro, 9,7 \% da população vivem abaixo da linha da pobreza (IBGE 2010).

Segundo dados da Organização das Nações Unidas (ONU, 2012), o Brasil é um dos maiores produtores de alimentos do mundo, mas enfrenta dificuldades em relação ao desperdício durante as etapas da cadeia produtiva. Com relação ao total dos desperdícios, estes já são percebidos na colheita do produto, que paira em torno de $10 \%$, prosseguindo nas 
etapas de transporte e industrialização, somando 50\%. Além dessas etapas, as perdas se estendem também para a comercialização (30\%) e, ainda 10\%, que são desperdiçados durante o seu preparo. (ONU, 2012) Para essa Organização, o Brasil desperdiça aproximadamente $64 \%$ da produção de alimentos gerada anualmente, o que incide diretamente na quantidade e na qualidade dos produtos.

As perdas pós-colheita podem ser definidas como aquelas que ocorrem após a colheita em virtude da falta de comercialização ou do consumo do produto em tempo hábil; ou seja, é um dano resultante à cultura, ocorridos após a sua colheita, acumulada desde o local da produção, somando-se aos deterioração ocorrida durante o transporte, armazenamento, processamento e /ou comercialização do produto vendável (CHITARRA; CHITARRA, 2005).

O manuseio pós-colheita envolve uma série de etapas, que vão desde a escolha do ponto ótimo de maturidade hortícola para a colheita, passando pela adoção de embalagens e métodos de resfriamento rápido adequados, até a tecnologias que permitam significativa agregação de valor como é o caso do processamento mínimo (CAMARGO, 2016).

Em conformidade com a Organização das Nações Unidas (ONU) para a Agricultura e Alimentação (FAO) apud Chitarra e Chitarra (2005), as causas primárias de perdas são: a) perdas biológicas, ocasionadas pelo consumo do vegetal por roedores, pássaros, entre outros animais que causam o desaparecimento do alimento; b) microbiológicas, devido a danos por fungos e bactérias; c) químicas, pelas reações químicas provocadas pelos constituintes do alimento, causando modificações na coloração, sabor, textura, valor nutritivo e, ainda, contaminação acidental por substâncias químicas; d) reações bioquímicas, mediadas por enzimas, gerando amolecimento ou descoloração; e) mecânicas, devido ao manuseio inadequado, como, cortes, abrasões, amassamentos, quedas; f) físicas, pelos extremos de calor ou frio; g) fisiológicas, que são alterações de caráter não parasitário que afetam as hortaliças, alterando seu metabolismo (respiração e transpiração) durante a maturação e senescência, acelerando as reações de deterioração; e h) psicológicas, devido à rejeição do consumidor pelo tipo de produto, tabu religioso ou intolerância alimentar culminando na redução do consumo.

As causas secundárias de perdas estão relacionadas à intervenção humana, como manuseio ou uso de tecnologias inadequadas ou insuficientes que levam às causas primárias de perdas, isto é, condições inadequadas de colheita, embalagem e manuseio incorreto; e falta de contentores adequados para o transporte e manuseio no carregamento e descarga. Além disso, o armazenamento, usualmente inadequado para proteger o produto, transporte (veículos e rodovias) inadequados; deficiência ou falta da cadeia de frio no transporte ou armazenamento; 
sistemas de comercialização tradicionais e deficientes; falta de legislação e ausência de padrões legais de qualidade para classificação ou sua não utilização; são fatores que causam rejeição de frutas e hortaliças (CHITARRA; CHITARRA, 2005).

Nesse sentido, o presente trabalho teve como objetivo identificar e qualificar as formas de desperdício que acontece através do mapeamento técnico, como também sensibilizar e conscientizar as pessoas que fazem parte do comercio local, para tentar minimizar este desperdício.

\section{Material e Métodos}

Como base metodológica utilizou-se o método hipotético-dedutivo, que de acordo com Karl Popper (1975), este método procura uma solução, mediante tentativas de erradicar os erros. (GIL, 1999) Com isso, desempenhou-se uma busca de dados, sobre o tema, local e material comercializado, dentro do ambiente que possibilitou uma contextualização e compreensão do assunto. Para um conhecimento no local (CEASA), foram realizadas visitas ao local de estudo.

Logo, houve a elaboração de um questionário (Figura 1) sobre práticas de pós-colheita, e a respeito do nível de conhecimento da população em relação ao desperdício no local, levando em consideração o que foi observado e estudado na etapa anterior. Essa inquirição foi aplicada tendo como formato uma entrevista pessoal, efetuados em horários pré-definidos, com o propósito de identificar as condições dos produtos e o nível de informação das pessoas.

Com conformidade no conhecimento de Bardin (2011), abordou-se uma análise de dados qualitativos, dispondo ao entrevistador um questionário que possibilite a fácil compreensão do ponto de vista, perspectiva e entendimento do entrevistado.

Após o questionamento realizou-se a tabulação e verificação dos dados, com o objetivo de fazer um levantamento dos principais fatores que geram desperdício e apontar técnicas ou possibilidades de redução percentual relacionado ao desperdício dos alimentos comercializados no local.

Para abordagem quantitativa utilizou-se a estatística descritiva com o auxílio do programa Excel, que possibilita a elaboração de gráficos e demonstrações de percentuais, médias, entre outros.

Na identificação de possíveis falhas nos processos pós-colheita (manuseio, embalagem, acondicionamento nos transportes), realizou-se visitas de campo e observou algumas fazendas, bem como, aplicou questionários específicos para os proprietários (Figura 2), obtendo uma tabulação dos dados 
Figura 1. Questionário mercado produtor sobre perdas de frutas e hortaliças na pós colheita em geral.

1- Qual atividade você exerce no mercado do produtor?

$\begin{array}{llll}\text { a) Transportador } & \text { b) Comerciante } & \text { c) Comprador local d) Agente e) Outros }\end{array}$

2- Qual a importância do CEASA na sua vida?

a) Extrema importância b) Importante c) Pouco importante d) Indiferente

3- Você sabe que no Brasil $40 \%$ das frutas e hortaliças são desperdiçadas antes de chegar à mesa do consumidor?

$\begin{array}{lll}\text { a) } & \text { Sim Não } & \text { c) Já escutei algo sobre }\end{array}$

4- Você sabia que há um grande desperdício de alimentos neste local?

$\begin{array}{lll}\text { a) } & \text { Sim Não } & \text { c) Imagino }\end{array}$

5- Este desperdício te preocupa de alguma forma?

a) Muito b) Moderadamente c) Pouco d) Não me importa

6- Você tem ou teve algum conhecimento sobre frutas e hortaliças para trabalhar aqui?
a) Muito conhecimento
b) Muito
c) Pouco
d) Não tenho

7- Você acha importantes as formações das pessoas que trabalham com frutas e hortaliças?

$\begin{array}{lll}\text { a) } \quad \operatorname{Sim} & \text { b) Não } & \text { c) Indiferente }\end{array}$

8- $\quad$ Teria interesse em aprender como manusear frutas e hortaliças para diminuir as perdas dos seus produtos?

$\begin{array}{lll}\text { a) } \quad \operatorname{Sim} & \text { b) Não } & \text { c) Indiferente }\end{array}$

Fonte: Própria (2018).

Figura 2. Questionário sobre as técnicas pós-colheita realizado nas fazendas visitadas.

\begin{tabular}{|ll|}
\hline $1-$ & Qual atividade você exerce neste local? \\
$2-$ & Qual sua formação? \\
$3-$ & Em que período é feita a colheita? \\
$4-$ & Que tipo de colheita é realizada? \\
$5-$ & Em que etapas da cadeia produtiva as perdas pós-colheita são mais problemáticas? \\
$6-$ & Qual a estimativa de desperdício em relação a cultivar? \\
$7-$ & O que é feito com o refugolresíduos? \\
$8-$ & Quais os impactos financeiros gerados por essa perda? \\
$9-$ & Você sabia que a fome no Brasil e no mundo, estão diretamente ligadas a essa perda e a má \\
distribuição? & $\quad$ Você concorda que boas técnicas de pós-colheita podem minimizar esse desperdício? \\
$10-$ & $\quad$ que é feito na fazenda para minimizar esse desperdício? \\
$11-$ &
\end{tabular}

Fonte: Própria (2018). 
Com os resultados dos questionários e visitas, elaborou-se panfletos informativos, o qual foi distribuído no local em conjunto intercorreu a realização de palestras informais em pequenos grupos, com o objetivo de sensibilizar as pessoas. Além disso, efetuou-se uma confecção de cartazes para serem fixados de forma aleatória dentro do mercado como instrumento de conscientização. Ademais, realizou-se métodos de análise documental e observação, completando a pesquisa.

\section{Resultados e Discussão}

Foi realizada uma conversa informal com a direção Geral do CEASA Juazeiro-Ba e visita ao centro de abastecimento, buscando identificar o ponto de vista da direção sobre o desperdício, assim como perceber as dificuldades que a Associaçãolgestão tem em relação ao tema. Nesse primeiro momento foi percebida a falta de um programa de beneficiamento dos vegetais nos estádios mais avançados de maturação, bem como ausência de parcerias para sua realização, além da dificuldade de conscientização da população que transita naquele comércio. Segundo a gestão do local, lá são produzidos aproximadamente 19 toneladas de resíduos por mês, onde $69 \%$ é constituído de alimentos. Ele relatou que os resíduos do local não são recolhidos de forma seletiva e seu destino é o aterro sanitário da cidade.

Salienta-se que estes resíduos poderiam ser reutilizados/trabalhados em forma de adubo orgânico, ao invés de ser meramente descartado em aterros sanitários. Burkot (2015) menciona que todo o material proveniente das centrais de abastecimento pode ser aproveitado ou reutilizado de diferentes formas, de acordo com seu grau de maturação.

Uma prática adotada pela gestão é a adaptação de espaços para o despejo dos resíduos, havendo a possibilidade de serem coletados pelos agentes de limpeza do estabelecimento e direcionados ao destino final. Além disso, os comerciantes que não organizam seus resíduos, são multados e notificados. Porém, ainda há muitos resíduos jogados pelo chão.

Dentro do CEASA encontram-se diversos boxes comerciais, que vão de pequenos a grandes produtores, e existe a venda de outros itens que não são frutas ไhortaliças. Para realizar atividades dentro do local é necessário um cadastramento oficial da empresa, o qual se faz necessário uma certificação da Agência Nacional de Vigilância Sanitária (ANVISA) e um alvará de funcionamento, já nos casos de pequenos produtores, o cadastro é feito com CPF e comprovante de residência.

No Mercado não existe espaços definidos para cada classe de alimento, assim como não possui uma separação entre varejo, atacado e caminhões, para aqueles que não possuem o boxe. 
Segundo o diretor do local, há um programa de mudança de espaço físico do CEASA para outra área maior e mais adequada, já que o local atual $(8,4$ ha) não suporta a população.

Para a Associação Brasileira das Empresas de Refeições Coletivas - ABERC (2018) as centrais de abastecimento devem possibilitar as condições que garantam a proteção dos alimentos e redução ao mínimo das perdas.

O CEASA funciona de segunda à sábado, a partir das 03h da manhã, exceto na segunda cujo horário de abertura é as 00h, pois no domingo não funciona.

A corporação não tem a rastreabilidade dos produtos comercializados, pois recebem alimentos de diversos locais e estados; fator esse que está diretamente ligado ao desperdício. Desta maneira, Soares (2014) revela que a falta de planos de ações logísticos eficazes aliados às más condições das estradas fazem com que $30 \%$ da safra colhida seja desperdiçada do campo ao consumidor.

Seguindo os métodos do estudo, após a aplicação dos questionários, pôde-se observar que a maioria das pessoas que frequentam e utilizam o local eram sequencialmente: $45.5 \%$ comerciantes, seguidos de $32.75 \%$ transportadores, e $24 \%$ compradoreslatravessadores, os quais classificam o CEASA como sua grande fonte de renda (Figura 3).

Figura 3. Conhecimento das pessoas relacionado ao desperdício e a importância que isso significava para elas.

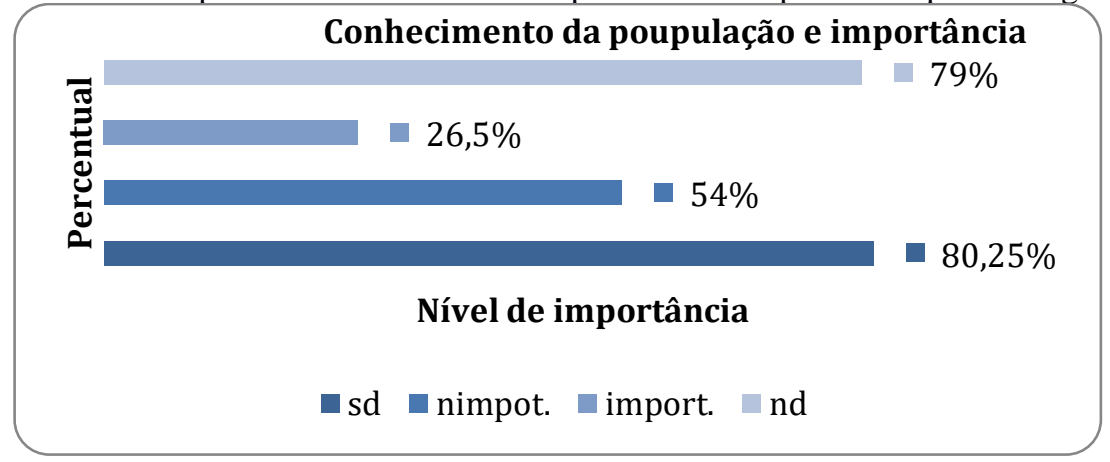

Leg. - nd: não sabia do desperdício; sd: sabia do desperdício; import: se importava com o desperdício; nimport: não se importava com o desperdício.

Fonte: Própria. (2018).

Constatou-se que a população tem conhecimento do desperdício produzido e ao mesmo tempo demonstraram não se importar com as consequências que este amontoado pode causar. Ademais, observou-se que, aproximadamente 93\%, não possuía conhecimentos específicos sobre técnicas pós-colheita como: manusear, transportar e armazenar estes alimentos, e também mostraram uma falta de interesse em adquirir essa compreensão, já que este conhecimento não 
é exigido para se trabalhar no local, o que influencia diretamente na alta produção de resíduos alimentares.

Percebeu-se que mesmo sendo multados, quando a fiscalização acontecia, a maioria dos indivíduos não separavam seus resíduos, apenas eram jogados pelo chão, obtendo como resultado um aumento no resíduo gerado, devido ao aumento de problemas com pragas urbanas. Convém salientar, entretanto, que uma pequena parte o recolhe os resíduos e o destina à animais como refeição (Figura 4).

Figura 4. Resultado da análise sobre o destino dos resíduos gerados.

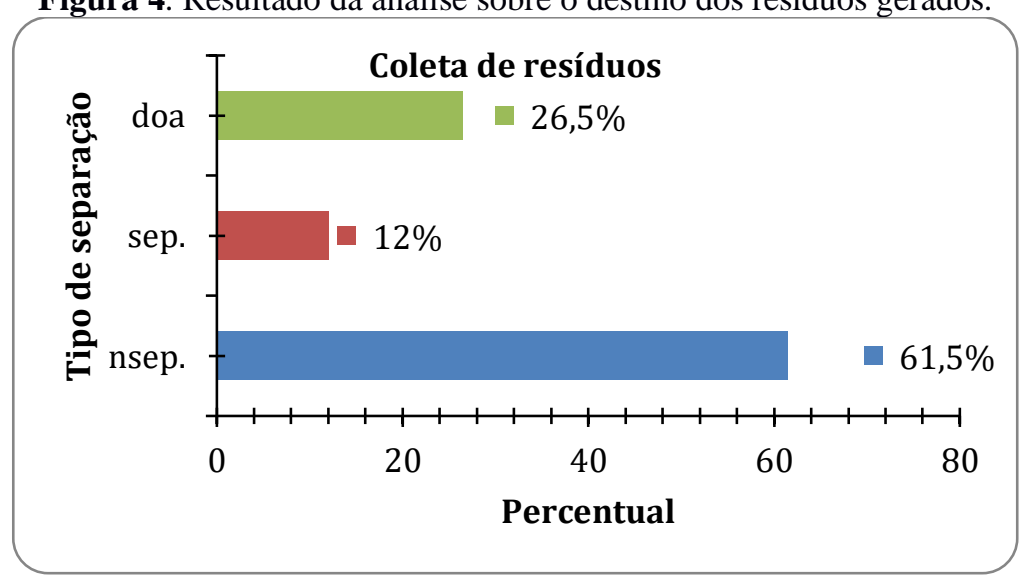

Leg. 2 - doa: doação; sep.: separa seus resíduos; nsep: não separa seus resíduos. Fonte: Própria (2018).

Pôde-se observar que o principal fator do desperdício ou geração de resíduos na CEASA Juazeiro são os produtos machucados e consequentemente deteriorados em partes. Esta situação pode ser explicada, muito provavelmente, pelo fato de quase metade dos produtos comercializados na central serem oriundos de outros estados e sendo assim, são submetidos ao transporte rodoviário. Para Silva e Bazoli (2017) o transporte é um fator que gera grandes índices com perdas de alimentos. Apenas $4 \%$ dos entrevistados declararam que receberam algum tipo de orientação sobre técnicas pós colheita, enquanto $81 \%$ relatou não ter recebido nenhuma orientação e $15 \%$ se mostraram indiferentes em relação ao assunto. Estes resultados influenciam diretamente na contribuição de formação de resíduos no local, uma vez que quanto menor o nível de conhecimento na área, maiores são as chances do alimento se tornar não aceitável comercialmente na central

Segundo Southerton e Yates (2015), o desperdício de alimentos só pode ser plenamente compreendido quando abordado dentro do conjunto mais amplo de processos socioculturais que afetam a alimentação contemporânea. 
Assim, a partir dos dados obtidos, foram elaborados folders (Figura 5) para servir como instrumento de sensibilização e disseminação de conhecimento. Distribuídos no local juntamente com uma palestra informal à partir de pequenos grupos, pois o CEASA não disponibilizava um espaço físico para realização de uma palestra formal. Com isso, foram concedidos 400 panfletos e estima-se um alcance de aproximadamente 800 pessoas.

Figura 5. Folder informativo com técnicas pós-colheita.
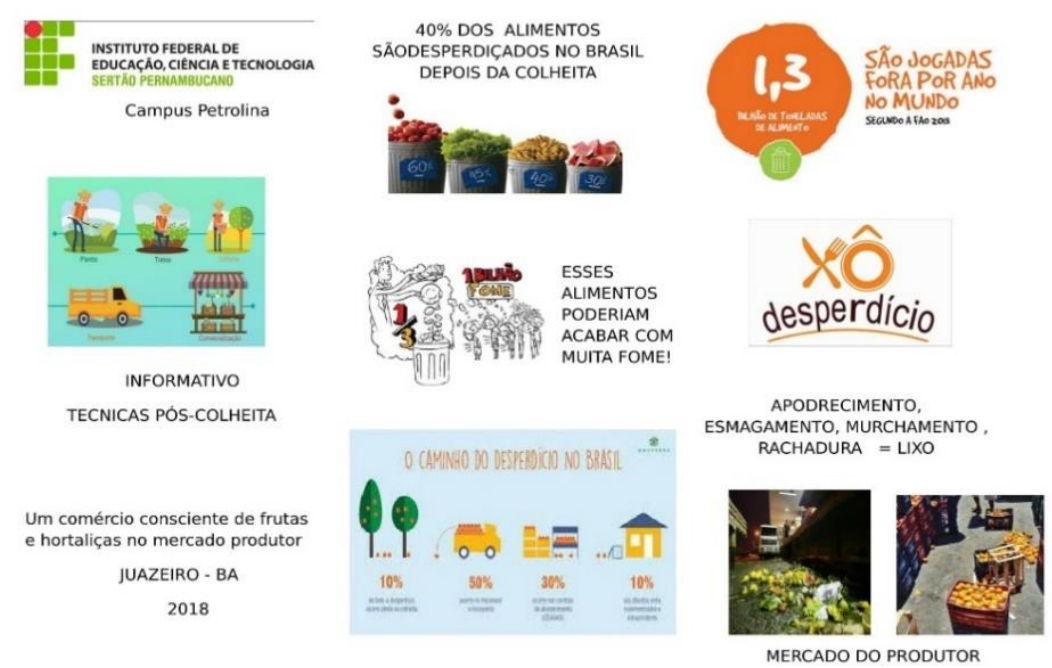

Fonte: Própria (2018).

Direcionando o estudo à algumas fazendas produtoras visitadas no vale do São Francisco, também foi realizada a aplicação de um questionário específico sobre técnicas póscolheita nas propriedades, com o objetivo de identificar alguma relação com o aumento de resíduos no CEASA (Figura 6).

De acordo com os resultados, constatou-se que praticamente todas as propriedades visitadas possuíam profissionais capacitados que tinham conhecimentos sobre pós-colheita e os colocavam em pratica. Como também, disponibilizavam para seus funcionários cursos e treinamento sobre o tema, a fim de minimizar as perdas no local.

Além disso, pôde-se identificar que há pouca produção de resíduos e de refugos nas propriedades, pois encaminhavam para algum tipo de reutilização em indústrias. Chegando à conclusão que o desperdício nas fazendas visitadas pode ser considerado não significativo.

Houve a realização de uma análise comparativa entre as fazendas e o CEASA, pois apesar das empresas se tratarem de caráter distintos, a diretoria da Agência Municipal do Meio Ambiente (AMA) também tem condições de se organizar como entidade, que presta serviços ao município, e juntamente com parcerias, realizar atividades em prol da diminuição dos resíduos alimentares. Segundo estudos similares na CEASA de Serra IRS, os autores mostram 
que esse tipo de trabalho pode ser realizado em qualquer outra central. (DALEGRAVE et. al., 2017).

Figura 6. Avalição de técnicas pós-colheita utilizadas nas fazendas e a relação de profissionais capacitados.

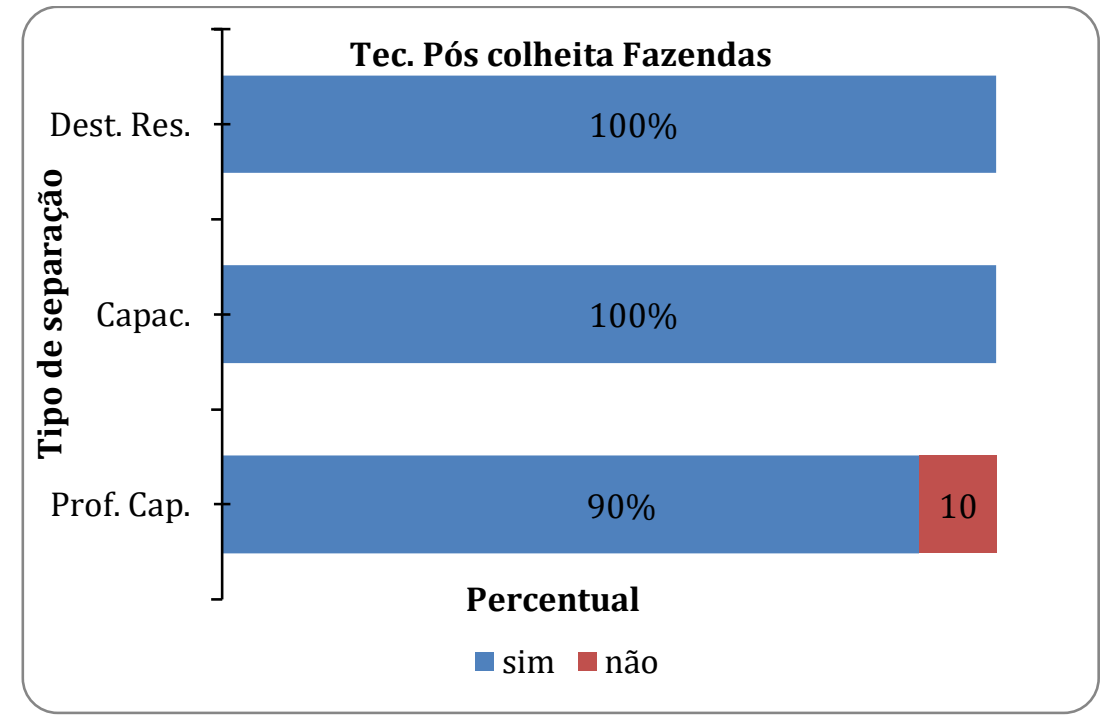

Leg.3 - prof.cap.: Presença de um profissional capacitado; capac: ofereciam cursos e palestras de capacitação; dest.res.: destinavam seus resíduos para indústria.

Fonte: Própria (2018).

Além das atividades realizadas, foram aplicados cartazes (Figura 7) com o intuito de sensibilizar e estimular o pensamento crítico, sobre a situação atual de desperdício, como também conscientizar a população em relação ao tema. Foram confeccionados cartazes de tamanhos médios, que tivesse uma fácil visualização e entendimento a uma curta distância, com a finalidade de chamar a atenção de quem passasse por perto. Eles foram espalhados uniformemente por todo o espaço físico da entidade tendo como proposito um alcance máximo de visualizações. Nesta última fase do projeto, pôde-se perceber uma atenção maior à realização das atividades pelas pessoas no local, pois as pessoas se manifestavam apoiando o trabalho, mostrando resultados positivos ao projeto. Com isso, foi realizada uma última visita ao local, após um mês de aplicação dos cartazes e estes ainda se encontravam aderidos as paredes.

$\mathrm{Na}$ busca pela conscientização da população este estudo levou ao público aspectos sociais, culturais e econômicos através da execução de atividades e disseminação de conhecimento, proporcionando um despertar e senso crítico sobre o assunto abordado.

Cunha et. al. (2019) avaliaram a necessidade da articulação social, governamental e dos gestores da instituição, uma vez que programas desenvolvidos nas centrais de abastecimento possuem expressiva relevância em termos de ganhos sociais. 
Figura 7. Cartaz utilizado com o objetivo de promover a sensibilização das pessoas sobre o desperdício de alimentos.

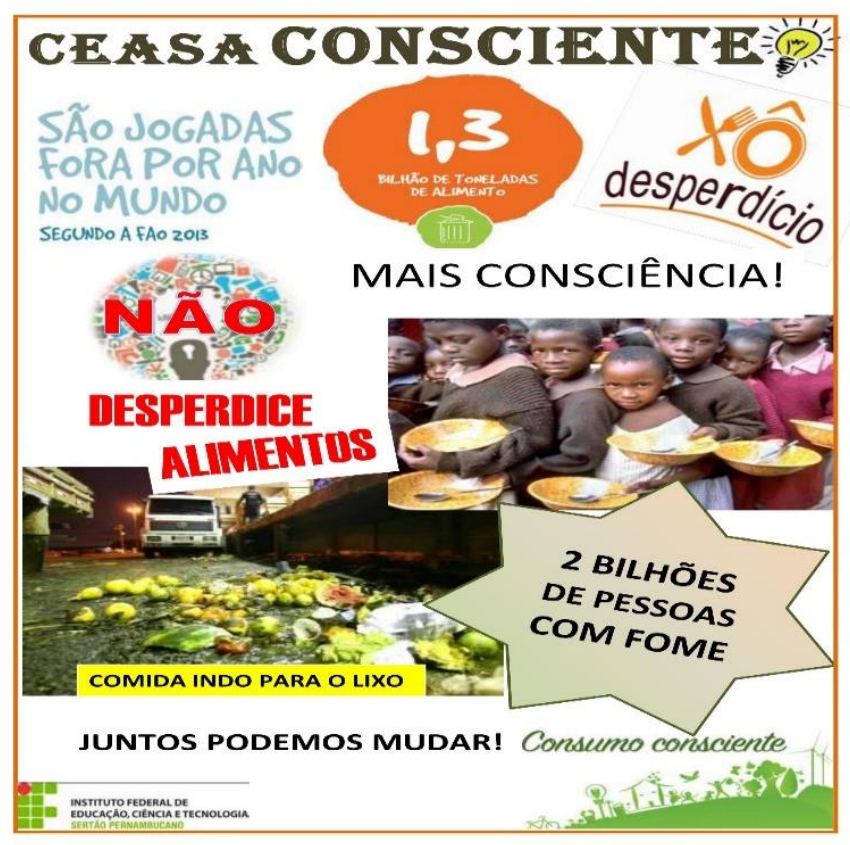

Fonte: Própria (2018).

Foi possível identificar que, os maiores fatores geradores dos resíduos na central são a falta de conhecimento técnico e consciência pessoal. Mas que em contra partida atividades como a realização de projetos como este, geram um despertar e fazem com que a comunidade possa, enxergar alguns problemas e atitudes, que de certa forma já se tornaram comuns e involuntários.

Recomenda-se que para estudos futuros, tente-se realizar a aplicação da coleta seletiva no local e um programa de destino ou beneficiamento dos resíduos, formando parcerias com empresas e a prefeitura, que além de identificar os meios causadores da expansão desses resíduos, estes possam ser reutilizados e não descartados como lixo.

\section{Conclusões}

A falta de conhecimento técnico e conscientização populacional sobre boas práticas de manipulação pós-colheita de vegetais pode ser o principal motivo gerador do desperdício alimentar no CEASA de Juazeiro-BA.

Necessita-se a realização de mais trabalhos que busquem a sensibilização sobre a perda de alimentos e os impactos gerados dessa ação.

Vale salientar, desta forma, que trabalhos de extensão e conscientização são essenciais para a democratização do acesso a informação. 
Recomenda-se para trabalhos futuros realização de metodologias de maior impacto para resultados mais positivos. Além de parcerias entre empresas de beneficiamento para destinação dos resíduos gerados.

\section{Referências}

ABERC. (2018) ASSOCIAÇÃO BRASILEIRA DAS EMPRESAS DE REFEIÇÕES COLETIVAS. Unidade de Alimentação e Nutrição condições estruturais: edifícios e instalações. In: - Manual prático de elaboração e serviço de refeições para coletividade. Disponivel em: https://aberc.com.br/.

BARDIN L. L'Analyse de contenu. Editora: Presses Universitaires de France, 1977. Análise de conteúdo. SP: Edições 70, 2011

BURKOT, C. R. \& AHRENS, R. B. (2015). Avaliação de Aproveitamento dos resíduos agrícolas para a produção de briquetes ecológicos. Revista Brasileira de Tecnologia Agroindustrial, 9(2), 1860-1874.

CAMARGO, LEANDRO NEVES. Manual pós-colheita da fruticultura brasileira. Londrina: Eduel, 2016. Disponível em: http://www.eduel.com.br.

CENCI, S. A; SOARES, A. G.; FREIRE JUNIOR, M. Manual de perdas pós-colheita em frutos e hortaliças. Rio de Janeiro: EMBRAPA-CTAA, 1997. 29p. (EMBRAPA-CTAA. Documentos, 27).

CENCI, S A. Boas Práticas de Pós-colheita de Frutas e Hortaliças. Brasília: Embrapa $\begin{array}{lllll}\text { Informação } & \text { Tecnológica } & \text { p. } & \text { 67-80, } & \text { Disponível }\end{array}$ em:http://www.ceasa.gov.br/dados/publicacao/pub09.pdf. Acesso em: 24 julho 2020.

CONAB- Companhia Nacional de Abastecimento. Juazeiro/BA integra parceria para prover dados sobre frutas e hortaliças ao Prohort. Juazeiro-Ba, 2019. Disponível em:https://www.conab.gov.br/ultimas-noticias/2989-juazeiro-ba-integra-parceria-para-proverdados-sobre-frutas-e-hortalicas-ao-prohort. Acesso em: 18 julho 2020. 
CUNHA, JOSÉ TAVARES \& JOÃO BATISTA M. R. NETO. Sistema de Gestão integrados: qualidade, meio ambiente, responsabilidade social, segurança e saúde no trabalho. Editora: SENAC. São Paulo, 2019.

CHITARRA, M. I. F.; CHITARRA, A. B. Pós-colheita de frutas e hortaliças: Fisiologia e manejo. 2. Ed. rev. e ampl. Lavras: UFLA, 2005. 785 p.

DALEGRAVE. Josué. et. Al. O desperdício de alimentos: um estudo de caso na CEASA Serra RS. Disponível em: http://ojs.fsg.br/index.php/pesquisaextensao/article/view/1751/1426. Acesso em: 27 julho 2020.

EMBRAPA. Manual de perdas pós-colheita em frutos e hortaliças p.06-22, 1997. Disponível em: http://poscolheita.cnpdia.embrapa.br/documents/36843/1212205/colheita_e_beneficiamento_ de_frutas_e_horalicas/efb05ffb-595e-4ec9-acfb-2375ca43e017. Acesso em: 06 julho 2020.

GIL, Antônio Carlos. Métodos e técnicas de pesquisa social. São Paulo: Atlas, 1999.

GUSTAVSSON, J. et al. Global food losses and food waste: extent, causes and prevention. Food and agriculture organization of the United Nations - FAO. 2011.

IBGE- Instituto Brasileiro de Geografia e Estatística. Cidades e Estados. Disponível em: https://www.ibge.gov.br/cidades-e-estados/ba/juazeiro.html. Acesso: 10 junho 2020.

JUAZEIRO, Portal. Mercado do produtor de Juazeiro. Disponível em: https://www6.juazeiro.ba.gov.br/negocios/. Acesso em: 08 julho 2020.

ORGANIZAÇÃO DAS NAÇÕES UNIDAS PARA AGRICULTURA E ALIMENTAÇÃO. FAO no Brasil 2017. Disponível em: http://www.fao.org/brasil/pt/. Acesso em: 28 julho 2020.

ORGANIZAÇÃO DAS NAÇÕES UNIDAS - ONU. FAO discute produção mundial de alimentos. FAO notícias 2012. Disponível em: https://nacoesunidas.org/ . Acesso em: 25 julho. 2020. 
PLANALTO- Presidência da República Casa Civil. DECRETO No 70.502, DE 11 DE MAIO DE 1972. Disponível em:http://www.planalto.gov.br/ccivil_03/decreto/19701979/D70502.htm. Acesso em: 22 julho 2020.

RICARDO, Francisco Duarte. et al. Análise do Agronegócio. Mercado agroexportador de fruticultura irrigada. Universidade Federal do Vale do São Francisco. Petrolina-PE. p. 35-37, 2016.

ROESCH, Sylvia Maria Azevedo. Projetos de Estágio e de Pesquisa em Administração. $3^{\text {a }}$. Ed. Ed. Atlas, 2005. São Paulo.

SILVA, M. M.; BAZOLI, T. N. Operações e Logística. São Paulo. Pearson Prentice Hall, 2017.

SOARES, Antônio Gomes. Desperdício de Alimentos no Brasil: um desafio político e social a ser vencido. Embrapa $\quad$ Disponível http://atividaderural.com.br/artigos/508fc56454d19.pdf. Acesso em: 28 julho. 2020.

SOUTHERTON, D.; YATES, L. Exploring food waste through the lens of social practice theories: some reflections on eating as a compound practice. In: EKSTROM, K. M. (Ed.). Waste management and sustainable consumption. London: Routledge, 2015. p. 133-149. 